MR WILLIAM KESTER ATKINS (Orcid ID : 0000-0003-1522-4691)

DR ROBERT J MCDOUGALL (Orcid ID : 0000-0003-2237-7231)

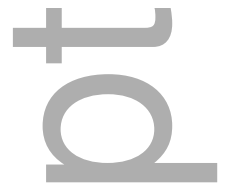

Article type : : Research Report

Editor Prof Francis Veyckemans

\title{
A DEDICATED RESPIRATORY FUNCTION MONITOR TO IMPROVE TIDAL VOLUME DELIVERY DURING NEONATAL ANAESTHESIA
}

William K Atkins ${ }^{1,2}$, Rob McDougall1,2,3, Elizabeth J Perkins ${ }^{1,4}$, Prue M Pereira-Fantini1,2, David G Tingay ${ }^{1,2,4}$

${ }^{1}$ Neonatal Research, Murdoch Children's Research Institute, Parkville, Australia

2 Department of Paediatrics, University of Melbourne, Melbourne, Australia

${ }^{3}$ Department of Anaesthesia, The Royal Children's Hospital, Parkville, Australia

${ }^{4}$ Department of Neonatology, The Royal Children's Hospital, Parkville, Australia

\section{Corresponding Author:}

William Kester Atkins BSci (Hons)

Neonatal Research

Murdoch Children's Research Institute

Royal Children's Hospital

Flemington Rd.

Parkville 3052 Victoria

Australia

+61393454023

+6139345 5067 (fax)

atkinsw@student.unimelb.edu.au

This is the author manuscript accepted for publication and has undergone full peer review but has not been through the copyediting, typesetting, pagination and proofreading process, which may lead to differences between this version and the Version of Record. Please cite this article as doi: 10.1111/PAN.13707

This article is protected by copyright. All rights reserved 
Article Category: Research Reports

Running title: RFM during neonatal anaesthesia

Manuscript word count: 3021 words

Keywords: Lung Mechanics, Mechanical Ventilation, Neonate, Infant, Tidal ventilation ra

Authors contributions: DGT, RMcD and PP-F developed the concept, designed the experiment and interpreted the data. WKA, EJP, RMcD and DGT were involved in study implementation. WKA and EJP performed data analysis. WKA initially reported the data as an honours thesis (University of Melbourne; DGT, RMcD supervisors) and wrote the first draft of the manuscript. All authors contributed to redrafting the manuscript.

\section{What is already known?}

Accurate monitoring of tidal volume reduces lung injury in neonatal infants requiring mechanical ventilation in the Neonatal Intensive Care Unit. Accurate neonatal respiratory function monitors are rarely used during neonatal anaesthesia, and tidal volume delivery is more variable than in the Neonatal Intensive Care Unit.

\section{What this article adds?}

Monitoring tidal volume delivery with a dedicated neonatal respiratory function monitor during anaesthesia care is feasible during all aspects of anaesthetic care, improves tidal ventilation delivery and may reduce the likelihood of delivering tidal volumes $<4 \mathrm{~mL} / \mathrm{kg}$ or $>10 \mathrm{~mL} / \mathrm{kg}$.

\section{ABSTRACT}

Background: Tight control of tidal volume using accurate monitoring may improve neonatal outcomes. However, respiratory function monitors incorporated in current anaesthetic workstations are generally inaccurate at tidal volumes used for infants.

Aims: To determine if a specific respiratory function monitor for neonatal infants improved expired tidal volume delivery during anaesthesia.

Method: Infants $<3$ months old requiring intubation for surgery in the Operating Theatre were studied. After intubation a Phillips NM3, Acutronic Florian or Novametrix Ventcheck Respiratory Function Monitor was integrated into the circuit, and clinicians given access to the display for the duration of anaesthesia. Breath-to-breath expired tidal volume delivery, leak and delivered pressure were recorded, with cardiorespiratory parameters. These were compared with a matched control group with clinicians blinded to respiratory function monitor display.

Results: A total of 10055 and 2569 inflations were measured in the respiratory function monitor visible $(n=32)$ and masked $(n=33)$ groups respectively, with mean (standard deviation) delivered 
expired tidal volume $7.5(2.4) \mathrm{mL} / \mathrm{kg}$ and 7.7 (3.0) $\mathrm{mL} / \mathrm{kg}$ respectively; mean difference $(95 \%$ confidence interval) $-0.2(-1.1,0.8) \mathrm{mL} / \mathrm{kg}$ (Welch's $\mathrm{t}$ test). In the visible group $55.6 \%$ of expired tidal volumes were between $4-8 \mathrm{~mL} / \mathrm{kg}$ compared to $51.7 \%$ in the masked group; Relative Benefit [95\% confidence interval] 1.08 [1.03, 1.12]. Expired tidal volume was less likely to be $<4 \mathrm{~mL} / \mathrm{kg}$ in the visible group compared to masked group; $6.4 \%$ versus $9.8 \%, 1.53[1.33,1.76]$. The use of a respiratory function monitor also reduced the number of inflations $>10 \mathrm{~mL} / \mathrm{kg} ; 13.0 \%$ versus $22.0 \%, 1.11$ $[1.09,1.14]$. Tidal volumes were higher during gastro-intestinal tract surgery than all other surgery in the respiratory function monitor visible group $(p=0.005)$.

Conclusions: Tidal volumes $<4 \mathrm{~mL} / \mathrm{kg}$ and $>10 \mathrm{~mL} / \mathrm{kg}$ are frequently delivered during neonatal anaesthesia. The inclusion of an accurate respiratory function monitor may reduce the risk of exposure to potentially harmful tidal volumes.

\section{Word Count: 300 words}

\section{INTRODUCTION}

Positive pressure ventilation (PPV) via an endotracheal tube (ETT) remains the primary method of respiratory support during anaesthesia of neonates and small infants. ${ }^{1}$ Developmental characteristics such as reduced alveolarisation and increased chest wall compliance render the neonatal infant particularly susceptible to ventilator induced lung injury. ${ }^{2}$ Ventilator induced lung injury has been attributed to both inadequate (atelectasis) and excessive (volutrauma) tidal volumes during PPV. 3,4 Therefore, accurate tidal volume $\left(\mathrm{V}_{\mathrm{T}}\right)$ delivery is a critical determinant of any lung protective ventilation strategy. ${ }^{5}$

Preclinical and clinical studies performed in a neonatal intensive care unit (NICU) setting have demonstrated that $V_{T}$ of $4.0-8.0 \mathrm{~mL} / \mathrm{kg}$ during PPV achieves adequate gas exchange whilst minimising risks of ventilator induced lung injury. ${ }^{6,7}$ Furthermore, the standard adoption of PPV modes that target a specific $V_{T}$ by NICUs has significantly reduced $V_{T}$ variability, specifically exposure to $V_{T}$ $>8.0 \mathrm{~mL} / \mathrm{kg}^{8}$ and lung injury. ${ }^{9}$ Targeting $V_{\mathrm{T}}$ is dependent on respiratory function monitors (RFM) that accurately record the small absolute $V_{T}$ of newborn infants. RFM are considered minimum standard of care in the $\mathrm{NICU}, 10$ but there are few studies examining effective and safe $\mathrm{V}_{\mathrm{T}}$ delivery during care of the neonatal infant outside of the NICU.11,12 This suggests a need to evaluate whether RFM-based $V_{T}$ assessment also has a role in supporting lung protective ventilation in the operating theatre. We have previously demonstrated that the use of a portable neonatal RFM was feasible during neonatal anaesthesia, and identified a high rate of delivered $V_{T}>10.0 \mathrm{~mL} / \mathrm{kg} .{ }^{13}$

The refinement of lung protective ventilation during neonatal anaesthesia first requires determining if the availability of an accurate RFM changes clinician practice. Only then can it be determined what $V_{T}$ range is appropriate during neonatal anaesthesia. Based on our earlier observations, we hypothesise that the use of a dedicated neonatal RFM will reduce the likelihood of expired $V_{T}\left(V_{T e}\right)$ 
being delivered outside of $4.0-8.0 \mathrm{~mL} / \mathrm{kg}$ during anaesthetic care. During neonatal mechanical ventilation with an uncuffed endotracheal tube $\mathrm{V}_{\mathrm{Te}}$ provides the most accurate measure of delivered $V_{T}$ to the lung. ${ }^{8,9}$

The aim of this study was to determine if the availability of a neonatal RFM during intraoperative anaesthetic care of infants $<3$ months old reduced the variability of $\mathrm{V}_{\mathrm{Te}}$ delivery, as defined as an increase in the frequency of $\mathrm{V}_{\mathrm{Te}}$ delivery within $4.0-8.0 \mathrm{~mL} / \mathrm{kg}$, compared to infants in whom the clinical team could not access the RFM display. Our secondary outcome was to determine if a RFM was more useful in certain clinical settings, including different surgical types and methods of PPV.

\section{METHODS}

This prospective observational cohort study was performed in the operating theatre and the NICU of the Royal Children's Hospital, Melbourne, Australia, a regional referral neonatal surgical hospital. The study was approved by the Institutes Ethics in Human Research Committee, (\#35048B and 37030A) and prospective written parental consent obtained in all infants.

Infants $<3$ months old (or $<3$ months postmenstrual age if born $<37$ weeks gestation) were considered eligible if they were scheduled to undergo non-cardiac surgery under general anaesthesia and anticipated to require endotracheal intubation. Infants were not studied if the treating anaesthetist believed enrolment in the study would impact clinical care, or if the infant had an existing medical condition that would alter $\mathrm{V}_{\mathrm{Te}}$ delivery or respiratory management, such as congenital diaphragmatic hernia. The type and size of ETT and the mode of respiratory support were at the discretion of the anaesthetist, including the delivered $\mathrm{V}_{\mathrm{Te}}$ target.

A calibrated RFM (see below for technical description) was incorporated into the ventilator circuit either at the time they were intubated in the operating theatre, or 30 min prior to departing the NICU if already intubated. RFM monitoring continued until the infant was extubated post-surgery or 30 min after returning to PPV on the NICU. The RFM was used during all aspects of anaesthetic care including intraoperatively, during induction and intra-hospital transport. Intraoperative PPV was provided with the Aisys Carestation (GE Healthcare, Madison, Wisconsin) and a Parker Disposable Paediatric Anaesthetic Breathing Circuit circle system (Melbourne, Australia). During intra-hospital transport and induction infants were supported by either a Neopuff infant resuscitator T-piece manual pressure device (Fisher Paykel Healthcare, East Tamaki, New Zealand) or a T-piece anaesthetic flow inflating (FI) bag (Parker Healthcare, Melbourne, Australia). 
Infants were allocated to either a RFM masked (RFM MASK $_{\text {) }}$ or RFM visible (RFMVIS) group. Clinicians

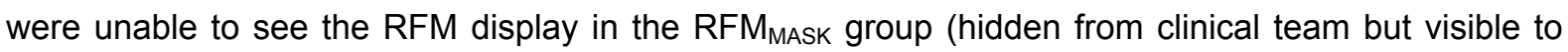
researchers). For the RFM VIS group, the RFM display was made available to clinicians and they were encouraged to access the displayed information, but not directed how to use the information provided.

The RFM MASK group included infants recruited from our recent prospective observational study of $\mathrm{V}_{\mathrm{TE}}$ during neonatal anaesthesia ${ }^{13}$ in which the RFM masked from clinicians ( $n=26$ infants; studied between April - August 2015). Before commencing our study this cohort was identified to have some limitations. All infants were inpatient on the NICU, and not representative of the entire infant population to be studied, which also included infants admitted directly to the operating theatre from home. To account for the broader inclusion criteria, potential for different demographic and clinical characteristics, the first 26 infants studied in the second cohort of 40 infants (April - September 2017) had the RFM visible. Thereafter the remaining 14 infants were allocated to the RFMVIS or RFM MASK group based on an interim analysis of demographic characteristics at enrolment, but not outcome parameters, in an attempt to ensure matching of important demographic and clinical characteristics, including disease severity, location of intubation and surgery type.

\section{RFM equipment}

The type of neonatal RFM available differed between the two study periods. In the first period only a Florian (Florian; Acutronic, Hirzel, Switzerland; hot-wire anemometer, flow accuracy $\pm 8.0 \%$ ) and Ventcheck 101 (Novametrix Medical Systems, Wallingford, Connecticut; fixed orifice differential pressure pneumotachometer, flow accuracy $\pm 3.0 \%$ ) RFM were available. During the second period a Phillips NM3 Respiratory Monitor (Phillips Respironics Hospital Respiratory Care, Foster City, CA), which measures flow and pressure using the same system and hardware as the Ventcheck, was used. The reason for the change was due to the availability of a battery (not present in the Florian) and inbuilt data saving capability (not available in the Ventcheck) in the NM3. The dead space of all devices was the same (approximately $1 \mathrm{~mL}$ ), and all RFM were calibrated immediately before use. Prior to the study, anaesthetic staff underwent training in the use of the RFM, including education on the 4.0-8.0 $\mathrm{mL} / \mathrm{kg} \mathrm{V}_{\mathrm{T}}$ target used in our NICU.

\section{Measurements and analysis}

Inspired and expired $\mathrm{V}_{\mathrm{T}}$ (post hoc converted to $\mathrm{mL} / \mathrm{kg}$ ), airway pressures and respiratory rate (RR) were recorded from the RFM. Heart rate, mean arterial blood pressure, peripheral oxygen saturation $\left(\mathrm{SpO}_{2}\right)$, end-tidal carbon dioxide $\left(\mathrm{EtCO}_{2}\right)$ and fraction of inspired oxygen $\left(\mathrm{FiO}_{2}\right)$ were recorded manually from a Phillips MP80 monitor (Phillips Healthcare, Eindhoven, Netherlands) or Aisys Carestation every five minutes throughout anaesthesia care. In addition, whether the treating anaesthetist had viewed the RFM in the last five minutes was recorded for the RFM vIS $_{\text {group. }}$ 
Demographic and manually recorded data were entered on the RedCap online database (Research Electronic Data Capture, Vanderbilt, USA) for later analysis.

Breath-to-breath data was acquired electronically from the NM3 and Florian. To account for variability in intra-operative duration, and the higher acquisition rates compared to the Ventcheck (manual recording every minute during transport and five-minutely intra-operatively), RFM data was decimated (PRISM V7.03, GraphPad Software Inc., San Diego, CA) to a maximum of 300 equally spaced inflations (the lowest number of intra-operative inflations recorded in an infant in the RFMvIs group) during each intra-operative period.

\section{Statistical Analysis}

Based on $49 \%$ of all inflations being delivered with a $\mathrm{V}_{\mathrm{Te}}$ between $4.0-8.0 \mathrm{~mL} / \mathrm{kg}$ in our initial study, ${ }^{13}$ 500 inflations within each group would be needed to detect an increase to $59 \%$ of inflation with the use of a RFM (alpha error of 0.05 and $80 \%$ power). To account for multiple samples from each infant (maximum 300/infant) a sample of 66 infants (33/group) was selected. All continuous data were tested for normality and analysed with robust standard error using a Welch's $t$ test. Categorical data was analysed using generalised linear models (binomial regression) to account for multiple samples from each subject and relative risk calculated for the primary outcome, and also $V_{T}$ delivery $<4.0$ $\mathrm{mL} / \mathrm{kg}$, and $>8.0$ and $>10.0 \mathrm{~mL} / \mathrm{kg}$. In our previous study we identified surgery of the gastrointestinal tract, intra-hospital transport and the use of the Neopuff versus the $\mathrm{FI}$ as factors that altered $\mathrm{V}_{T}$ delivery. Statistical analysis was performed with PRISM V7.03 and STATA, and a $p<0.05$ considered significant.

\section{RESULTS}

A total of 33 infants in the RFMVIS (10055 inflations) and 33 infants in the RFM MASK (2569 inflations) were enrolled and studied (eligibility and enrolment summarised in Supplementary Data Figure S1).

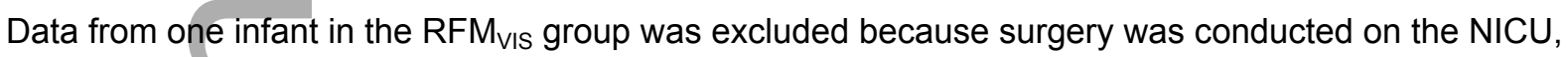
leaving a final population of 32 infants in the RFMVIS group. Table 1 describes the demographic or cardiorespiratory characteristics of the two groups. Three infants in each group had bronchopulmonary dysplasia. More infants in the RFM MASK group had ENT, maxillofacial or ophthalmological surgery. The mean duration of anaesthetic care was a mean (SD) 106 (61) and 104 (72) minutes in the RFM MASK and RFM $M_{V I S}$ groups respectively, with both having high intra-subject variability; range 25-264 (RFM $M_{\text {MASK }}$ ) and 26-332 (RFM $M_{V I S}$ ) minutes. The RFM $M_{V I S}$ group had a statistically higher, but not clinically significant, $\mathrm{EtCO}_{2}$ and $\mathrm{F}_{\mathrm{i}} \mathrm{O}_{2}$ during intra-operative care, with all other cardiorespiratory parameters being similar (Supplementary Data Table S1).

RFM Use

This article is protected by copyright. All rights reserved 
Overall the treating anaesthetist was observed viewing the RFM display at least every 5 min $60 \%$ of the time. This increased to $97 \%$ during the first 15 minutes of the intraoperative care and $89 \%$ during intra-hospital transport.

\section{$V_{T}$ delivery during anaesthesia care}

Figure 1 shows the $V_{T e}$ delivery for each infant. This ranged from $1.1-28.9 \mathrm{~mL} / \mathrm{kg}$ in the $R F M_{\text {MASK }}$ group (Figure $1 \mathrm{~A}$ ) and 1.0-27.3 $\mathrm{mL} / \mathrm{kg}$ in the RFM $\mathrm{VII}_{\mathrm{S}}$ group (Figure 1B). Overall mean (SD) delivered $\mathrm{V}_{\mathrm{Te}}$ was $7.5(2.4) \mathrm{mL} / \mathrm{kg}$ in the $\mathrm{RFM}_{\text {MASK }}$ group and 7.7 (3.0) $\mathrm{mL} / \mathrm{kg}$ in the RFM $\mathrm{VIS}_{\mathrm{S}}$ group (Figure 2). Gestational age and weight did not influence $\mathrm{V}_{\mathrm{Te}}$ (Supplementary Data Figure S2).

Infants in the $R F M_{V I S}$ group were more likely to have $\mathrm{V}_{\mathrm{Te}}$ delivered between $4.0-8.0 \mathrm{~mL} / \mathrm{kg} ; 55.6 \%$ versus $51.7 \%$ (Table 2), but this was not significant when accounting for multiple samples from each subject; Relative Risk [95\% Cl] 1.08 [0.83, 1.41] (logistic regression). There was no difference in the proportion of $\mathrm{V}_{T_{\mathrm{e}}}>8.0 \mathrm{~mL} / \mathrm{kg}$, being $38.5 \%$ in the $R F M_{\text {MASK }}$ and $38.5 \%$ in the $R F M_{V I S}$ group, or $V_{T e}$ $<4.0 \mathrm{~mL} / \mathrm{kg}(9.8 \%$ vs $6.4 \%)$. There was a significant reduction in the proportion of inflations $>10.0$ $\mathrm{mL} / \mathrm{kg}$ in the RFM VIS group; $13.0 \%$ compared to $22.0 \%$; Relative Risk $0.61(0.42,0.89)$.

$V_{T}$ delivery during different surgical procedures

Overall $\mathrm{V}_{\mathrm{Te}}$ delivery was a mean $[95 \% \mathrm{Cl}] 1.1[0.3,2.0] \mathrm{mL} / \mathrm{kg}$ (Welch's $\mathrm{t}$ test) higher during gastrointestinal surgery (excluding inguinal hernia repair) compared to all other surgical procedures. This was due to a difference in the RFM VIS $_{\text {group }}(p=0.005$, Figure $3 A$ ) but not the RFM MASK group $(p=0.87)$.

$V_{T}$ delivery during intra-hospital transport

Of the 28 infants monitored during transport there was no difference in mean (SD) delivered $V_{T e}$ delivery during intra-hospital transport; RFM MAsK 7.3 (4.9) $\mathrm{mL} / \mathrm{kg}(\mathrm{n}=19)$ versus RFM $\mathrm{VIS}_{\mathrm{S}} 7.9$ (3.1) $\mathrm{mL} / \mathrm{kg}(\mathrm{n}=9), p=0.44$ (Figure 3B). There was no statistical difference in the delivered $V_{T e}$ during support with a Neopuff T-piece $(p=0.87)$ or FI bag $(p=0.65)$ between the RFMVIS and RFM MASK groups. Delivered $V_{\text {Te }}$ was $8.4(3.5) \mathrm{mL} / \mathrm{kg}(\mathrm{n}=5)$ with the $\mathrm{FI}$ bag and $7.5(2.7) \mathrm{mL} / \mathrm{kg}(\mathrm{n}=5)$ with the Neopuff in the RFM VIS group, and $10.3(7.4) \mathrm{mL} / \mathrm{kg}(\mathrm{n}=5)$ and $6.4(2.8) \mathrm{mL} / \mathrm{kg}(\mathrm{n}=14)$ respectively in the RFM MASK group (Figure $3 C$ ).

\section{DISCUSSION}

Our study found that the use of a RFM capable of monitoring the small tidal volumes of the neonatal lung decreased the proportion of delivered $\mathrm{V}_{\mathrm{Te}}>10.0 \mathrm{~mL} / \mathrm{kg}$ during anaesthetic care. Although a greater percentage of $V_{T e}$ were delivered between $4.0-8.0 \mathrm{~mL} / \mathrm{kg}$, and less $<4.0 \mathrm{~mL} / \mathrm{kg}$, when a RFM was used these differences were not statistically significant. RFM monitoring of tidal volume within the operating theatre was feasible, as was monitoring during intra-hospital transport. The results of this study suggest that accurate monitoring of neonatal tidal ventilation during anaesthetic care can be 
achieved. This is the first step in ensuring delivery of age-appropriate $V_{T}$ ranges during surgical procedures.

Access to an accurate RFM did not increased the proportion of inflations delivered between 4.0-8.0 $\mathrm{mL} / \mathrm{kg}$ during intra-operative care, a $\mathrm{V}_{\mathrm{Te}}$ range advocated in the NICU. ${ }^{10}$ The use of a RFM did decrease the proportion of inflations at the extremes of $V_{T e}$. Tidal volumes of $<4.0$ and $>10.0 \mathrm{~mL} / \mathrm{kg}$ decreased from $31.8 \%$ to $19.4 \%$, values often attributed to impaired gas exchange, atelectasis and over-distension in the NICU. ${ }^{14-16}$ This suggests that anaesthetic staff were using the RFM to guide and adapt clinical care. We have previously shown that a dedicated neonatal RFM provides more accurate $V_{T E}$ measures than monitoring available within a commercial anaesthetic machine. ${ }^{13}$ The availability of battery-powered, low dead space RFM systems offers a practical solution during neonatal anaesthesia, where location of care and other interventions, such as opening of the abdomen, create rapid changes in thoraco-abdominal compliance and a need for a more dynamic approach to mechanical ventilation.

Although the use of an RFM reduced the proportion of $\mathrm{V}_{\mathrm{Te}}>10.0 \mathrm{~mL} / \mathrm{kg}$, there was no difference in the proportion of $\mathrm{V}_{\mathrm{Te}_{\mathrm{e}}}>8.0 \mathrm{~mL} / \mathrm{kg}$ between the two groups. This reflects the overall relatively high delivered $\mathrm{V}_{\mathrm{Te}}$ in both groups (7.0-8.0 mL/kg), compared to a mean (SD) $\mathrm{V}_{\mathrm{Te}} 4.2(0.7) \mathrm{mL} / \mathrm{kg}$ in a recent report of $\mathrm{V}_{\mathrm{T}}$ delivery for neonates ventilated solely within our NICU. ${ }^{8}$ The lack of difference, and relatively high, mean $\mathrm{V}_{\mathrm{Te}}$ values observed between the RFM $\mathrm{V}_{\mathrm{VIS}}$ and RFM not designed to determine if the delivered $\mathrm{V}_{T e}$ was clinically appropriate for each infant nor what $\mathrm{V}_{T e}$ may be lung protective during anaesthetic care. It is possible that $4.0-8.0 \mathrm{~mL} / \mathrm{kg}$ is not appropriate and clinicians were intentionally targeting higher $V_{T}$. Given the infants were stable during the intraoperative period it suggests that clinicians were delivering an effective $\mathrm{V}_{\mathrm{Te}}$. This observation does highlight the potential risk of translating protective ventilation parameters from one clinical environment, such as the NICU, to another. The ability of accurate $\mathrm{V}_{\mathrm{Te}}$ monitoring allows future research to delineate the optimal lung protective $\mathrm{V}_{\mathrm{T}}$ range during neonatal surgery.

Although our study was not powered or designed to investigate $\mathrm{V}_{\mathrm{Te}}$ delivery during different types of surgery the observation that both absolute $\mathrm{V}_{\mathrm{Te}}$, and $\mathrm{V}_{\mathrm{Te}}$ variability, were higher in infants receiving a laparotomy, and specifically when the RFM was visible, is potentially important. It is plausible that higher $\mathrm{V}_{\mathrm{Te}}$ may be required during phases of surgery, such as when lung inflation may be restricted by $\mathrm{CO}_{2}$ insufflation to separate the viscera, ${ }^{17}$ during surgical manipulation of bowel or when intraperitoneal fluid is increased after abdominal wall closure, and this may vary between ventilation using a cuffed and uncuffed ETT. Conversely transient removal of abdominal contents may result in unintentionally high $\mathrm{V}_{\mathrm{Te}}{ }^{18}$ It would not be practical to document the exact surgical and anaesthetic events occurring for all recorded inflations, but these findings indicates that clinicians should be aware that specific tidal volumes may need to be matched to the surgical procedure performed.

This article is protected by copyright. All rights reserved 
$89 \%$ of anaesthetists were observed using the RFM during intra-hospital transport. This result was comparable with that of a study monitoring the use of a RFM during inter-hospital transport. ${ }^{12}$ There are many similarities between inter and intra-hospital transport, but one key difference is how tidal ventilation is delivered. A mechanical ventilator is usually used during inter-hospital transport. In comparison manual T-piece devices are sometimes preferred in intra-hospital settings. We have previously demonstrated that $\mathrm{V}_{\mathrm{Te}}$ delivery is less variable using the Neopuff compared to a FI bag. ${ }^{13}$ The Neopuff is frequently used in the NICU, offering reliable control of inflation and deflation pressure. Unlike the NICU, FI bags are often used in anaesthetic care, offering rapid amendment to duration and magnitude of lung inflations, but our study further supports the argument that clinicians are unable to accurately deliver $\mathrm{V}_{\mathrm{Te}}$ within the low absolute values needed for the neonatal lung. Although caution should be applied to our results, as the number of infants was small, and the absolute $V_{T e}$ difference not significant, access to an RFM decreased the variability of $V_{T}$ delivery with a FI Bag more than any other mode of support. This is similar to a study of manual bag ventilation during neonatal resuscitation. ${ }^{19}$ Until further study of $\mathrm{V}_{\mathrm{Te}}$ delivery using a $\mathrm{FI}$ bag is performed we would advocate positive pressure support should be provided with an RFM.

This study has some additional limitations. The type of RFM was not standardised due to changes in device access. We contend that this is unlikely to impact on our results given the similar accuracy between the Florian and Ventcheck/NM3. However the lack of inbuilt data recording of the Ventcheck, resulted in fewer inflation recordings in the RFM MASK $_{\text {group, requiring the RFM }}$ data to be restricted to measurement of 300 inflations/infant intra-operatively. It is possible that this introduced a bias, but it is arguable that recorder bias would be greater if data were manually recorded in the RFMVIS group. Neonatal RFM require the integration of a pneumotachometer at the airway opening. This is essential for accuracy but does introduce additional equipment near the ETT, which may impact deadspace, accuracy of end-tidal $\mathrm{CO}_{2}$ monitoring and ETT security.

\section{Conclusion}

The use of a dedicated and accurate RFM is feasible during all aspects of neonatal anaesthetic care but did not increase the number of inflations delivered with a tidal volume 4.0-8.0 ml/kg. The use of a RFM did reduce tidal volume delivery $>10.0 \mathrm{ml} / \mathrm{kg}$. Further study is needed to determine the optimal $V_{T}$ values to target in infants needing surgery.

Ethics Approval: This study was approved by the Royal Children's Hospital Ethics in Human Research Committee (HREC 35084B, 37030A).

Financial Support: This study is supported by the Victorian Government Operational Infrastructure Support Program (Melbourne, Australia). DGT is supported by a National Health and Medical Research Council Clinical Career Development Fellowship (Grant ID 1053889). 
Competing interests: Teleflex (Sydney, Australia) supplied a loan Philips Respironics NM3 monitor for the duration of the study. The MCRI purchased all consumables. Teleflex had no involvement in study design, implementation, analysis, interpretation or reporting. The authors have no other competing interests to declare.

\section{REFERENCES}

1. Rimensberger P. Pediatric and Neonatal Mechanical Ventilation, 1 Edn: Springer-Verlag Berlin Heidelberg, 2015: 1642.

2. Schmolzer $G M$, te Pas $A B$, Davis $P G$, et al. Reducing Lung Injury during Neonatal Resuscitation of Preterm Infants. J Pediatr. 2008; 153(6):741-745.

3. Ramanathan $R$, Sardesai $S$. Lung protective ventilatory strategies in very low birth weight infants. J Perinatol. 2008; 28:S41-S46.

4. Numa AH, Newth CJL. Anatomic dead space in infants and children. J Appl Physiol. 1996; 80 (5):1485-1489.

5. Dreyfuss D, Saumon G. Barotrauma Is Volutrauma, but which volume is the one responsible. Intensive Care Med. 1992; 18(3):139-141.

6. Chowdhury O, Rafferty GF, Lee S, et al. Volume-targeted ventilation in infants born at or near term. Arch Dis Child Fetal Neonatal Ed. 2006; 97(4): 264-266.

7. Donn SM, Sinha SK. Minimising ventilator induced lung injury in preterm infants. Arch Dis Child-Fetal. 2006; 91(3):226-230.

8. Farrell O, Perkins EJ, Black D, et al. Volume guaranteed? Accuracy of a volume-targeted ventilation mode in infants. Arch Dis Child Fetal Neo Ed. 2018; 103(2):120-125.

9. Wheeler $\mathrm{KI}$, Klingenberg $\mathrm{C}$, Morley $\mathrm{CJ}$, et al. Volume-Targeted versus Pressure-Limited Ventilation for Preterm Infants: A Systematic Review and Meta-Analysis. Neonatology. 2011; 100(3):219-227.

10. Schmolzer GM, Kamlin OCOF, Dawson JA, et al. Respiratory monitoring of neonatal resuscitation. Arch Dis Child Fetal Neo Ed. 2010; 95(4):295-303.

11. Schmolzer GM, Morley CJ, Wong $C$, et al. Respiratory function monitor guidance of mask ventilation in the delivery room: feasiblity study. J Pediatr. 2012; 160(3): 377-381.

12. Lilley $C D$, Stewart M, Morley CJ. Respiratory function monitoring during neonatal emergency transport. Arch Dis Child Fetal Neo Ed. 2005; 90(1):82-83.

13. Abouzeid T, Perkins EJ, Pereira-Fantini PM, et al. Tidal Volume Delivery during the Anesthetic Management of Neonates Is Variable. J Pediatr. 2017; 184(3): 51-56.

14. Hong $\mathrm{CM}, \mathrm{Xu} \mathrm{DZ}$, Lu $\mathrm{Q}$, et al. Low tidal volume and high positive end-expiratory pressure mechanical ventilation results in increased inflammation and ventilator-associated lung injury in normal lungs. Anesth Analg. 2010; 110(6):1652-1660.

This article is protected by copyright. All rights reserved 
15. Parsons PE, Eisner MD, Thompson BT, et al. Lower tidal volume ventilation and plasma cytokine markers of inflammation in patients with acute lung injury. Crit Care Med. 2005; 33(1): $1-6$.

16. Severgnini P, Selmo G, Lanza $C$, et al. Protective mechanical ventilation during general anesthesia for open abdominal surgery improves postoperative pulmonary function. Anesthesiology. 2013; 118(6): 1307-1321.

17. Cunningham AJ. Laparoscopic surgery--anesthetic implications. Surg Endosc. 1994; 8(11):1272-1284.

18. Dierdorf SF, Krishna G. Anesthetic management of neonatal surgical emergencies. Anesth Analg. 1981; 60(4):204-215.

19. Wood FE, Morley CJ, Dawson JA, et al. A respiratory function monitor improves mask ventilation. Arch Dis Child Fetal Neo Ed. 2008; 93(5):380-381.

\section{TABLES}

Table 1. Subject characteristics

\begin{tabular}{|c|c|c|}
\hline 厂 & $\operatorname{RFM}_{\text {MASK }}(n=33)$ & $\operatorname{RFM}_{\mathrm{VIS}}(\mathrm{n}=32)$ \\
\hline Gestational Age (completed weeks) & $35.9(4.5)$ & $35.4(5.2)$ \\
\hline Corrected Gestational Age (completed weeks) & $40.8(3.9)$ & $42.8(4.7)$ \\
\hline Weight at study (g) & $3620(1188)$ & $4218(1308)$ \\
\hline Female, n (\%) & $9(27 \%)$ & $7(22 \%)$ \\
\hline \multicolumn{3}{|l|}{ Cardiorespiratory parameters at start of study } \\
\hline MABP $(\mathbf{m m H g})$ & $50(13)$ & $52(19)$ \\
\hline HR (bpm) & $138(19)$ & $144(16)$ \\
\hline $\mathrm{SpO}_{2}(\%)$ & $98(3)$ & $98(5)$ \\
\hline $\mathrm{EtCO}_{2}(\mathrm{mmHg})$ & $42.7(13.0)$ & $35.3(15.3)$ \\
\hline $\mathrm{FiO}_{2}(\%)$ & $0.5(0.3)$ & $0.7(0.3)$ \\
\hline \multicolumn{3}{|l|}{ Surgical procedure (body system; n) } \\
\hline ENT, Maxillo-facial and ophthalmological & 7 & 1 \\
\hline Chest (including oesophagus) & 1 & 2 \\
\hline Laparotomy* & 18 & 15 \\
\hline 7 & 2 & 4 \\
\hline Inguinal hernia & 5 & 7 \\
\hline Other (Limbs or non-cavity) & 0 & 3 \\
\hline
\end{tabular}

Abbreviations: MABP; mean arterial blood pressure, $\mathrm{HR}$; heart rate, $\mathrm{SpO}_{2}$; peripheral oxygen saturation, $\mathrm{EtCO}_{2}$ ' end-tidal carbon dioxide (mainstream), $\mathrm{FiO}_{2}$; fraction of inspired oxygen, ENT: ear nose and throat. All data mean (SD) unless indicated. * Surgery for conditions of the gastrointestinal 
tract that involved opening of the abdominal cavity and manipulation of the bowel, including atresia/any obstruction (RFM MASK $10 ; R_{\text {RFM }}$, 10), abdominal wall defects $(4 ; 1)$ and perforation/necrotising enterocolitis/abscess $(4 ; 4)$.

\begin{tabular}{|c|c|c|}
\hline$V_{\mathrm{T}}(\mathrm{mL} / \mathrm{kg}) \quad \mathrm{RFM}_{\text {MASK }}$ & $R_{F} M_{\text {VIS }}$ & Risk Ratio (95\% Cl) \\
\hline \begin{tabular}{l|l}
$<4.0$ & $9.8 \%$
\end{tabular} & $6.4 \%$ & $0.70(0.30,1.63)$ \\
\hline $51.7 \%$ & $55.6 \%$ & $1.08(0.83,1.41)$ \\
\hline $38.5 \%$ & $38.0 \%$ & $1.08(0.90,1.29)$ \\
\hline$>10.0$ & $13.0 \%$ & $0.61(0.42,0.89)$ \\
\hline
\end{tabular}

Table 2. Variability of $\mathbf{V}_{\mathrm{Te}}$ delivery

All data logistic regression accounting for multiple $V_{T e}$ values from each subject

\section{FIGURE LEGENDS}

Figure 1. Box and whisker plot of delivered $\mathrm{V}_{\mathrm{Te}}$ during the intraoperative period for each subject in the $\mathrm{RFM}_{\text {MASK }}$ group (A, $\mathrm{n}=33$ ) and $\mathrm{RFM}_{\mathrm{VIS}}$ Group $(\mathrm{B}, \mathrm{n}=32$ ). Boxes represent median and inter-quartile range with error bars minimum to maximum values. Shaded area indicates the $4.0-8.0 \mathrm{~mL} / \mathrm{kg} V_{T e}$ range targeted in the NICU.

Figure 2. $V_{T e}(m L / k g)$ for the $\operatorname{RFM}_{\text {MASK }}\left(n=33 ; 2569\right.$ inflations) and $R_{F M}$ ( $n=32 ; 10055$ inflations)

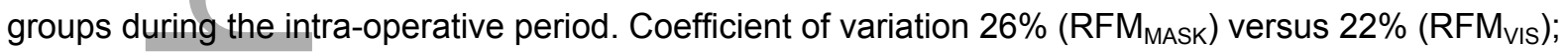
$p=0.32$, Welch's $t$ test. Boxes represent mean (SD) with error bars minimum to maximum values. Shaded area as per Figure 2. Mean [95\% Cl] difference $-0.18[-1.12,0.76) \mathrm{mL} / \mathrm{kg}$ (Welch's t test).

Figure 3. A. $V_{T e}\left(\mathrm{~mL} / \mathrm{kg}\right.$ ) delivery during GIT surgery (RFM $\mathrm{VIS}_{\mathrm{S}} \mathrm{n}=15 ; 4399$ inflations and $R F M_{\text {MASK}}$, $n=18 ; 1455$ inflations), compared to all other surgery types (RFM $M_{V I S}, n=17 ; 5651$ inflations and RFM $_{\text {MASK, }} \mathrm{n}=15 ; 1866$ inflations). *Mean [95\% Cl] difference $1.5[0.5,2.4] \mathrm{mL} / \mathrm{kg}$ (Welch t test). White boxes represent $\mathrm{RFM}_{\mathrm{VIS}}$ and grey boxes $\mathrm{RFM}_{\mathrm{MASK}}$. B. $\mathrm{V}_{\mathrm{Te}}$ delivery during intra-hospital transport for the RFM MASK $(n=19 ; 271$ inflations) and RFMVIS groups ( $n=9 ; 2583$ inflations), mean difference 0.9 [1.4, 3.1] $\mathrm{mL} / \mathrm{kg}$. C. $V_{T e}$ delivery during positive pressure ventilation with a $\mathrm{FI}$ bag $\left(\operatorname{RFM}_{\text {MASK }} n=5 ; 72\right.$ 
inflations and RFM $M_{V I S} n=5 ; 1055$ inflations) and Neopuff (RFM $M_{\text {MASK }} n=14 ; 210$ inflations and RFMVIS

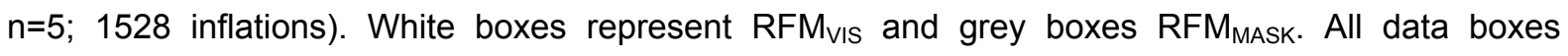
represent mean (SD) with error bars minimum to maximum.

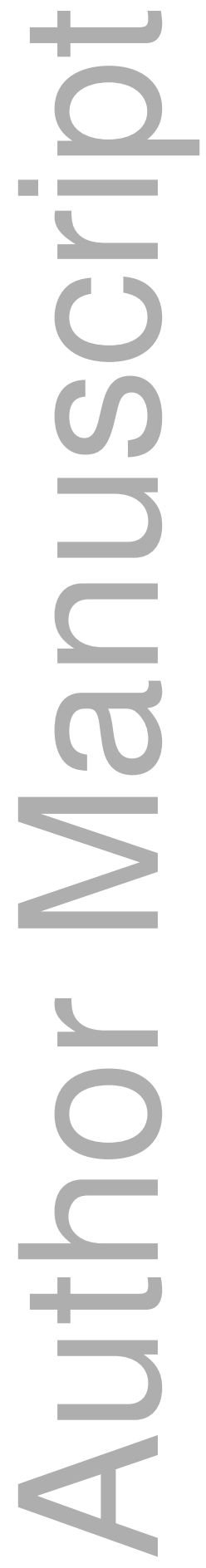



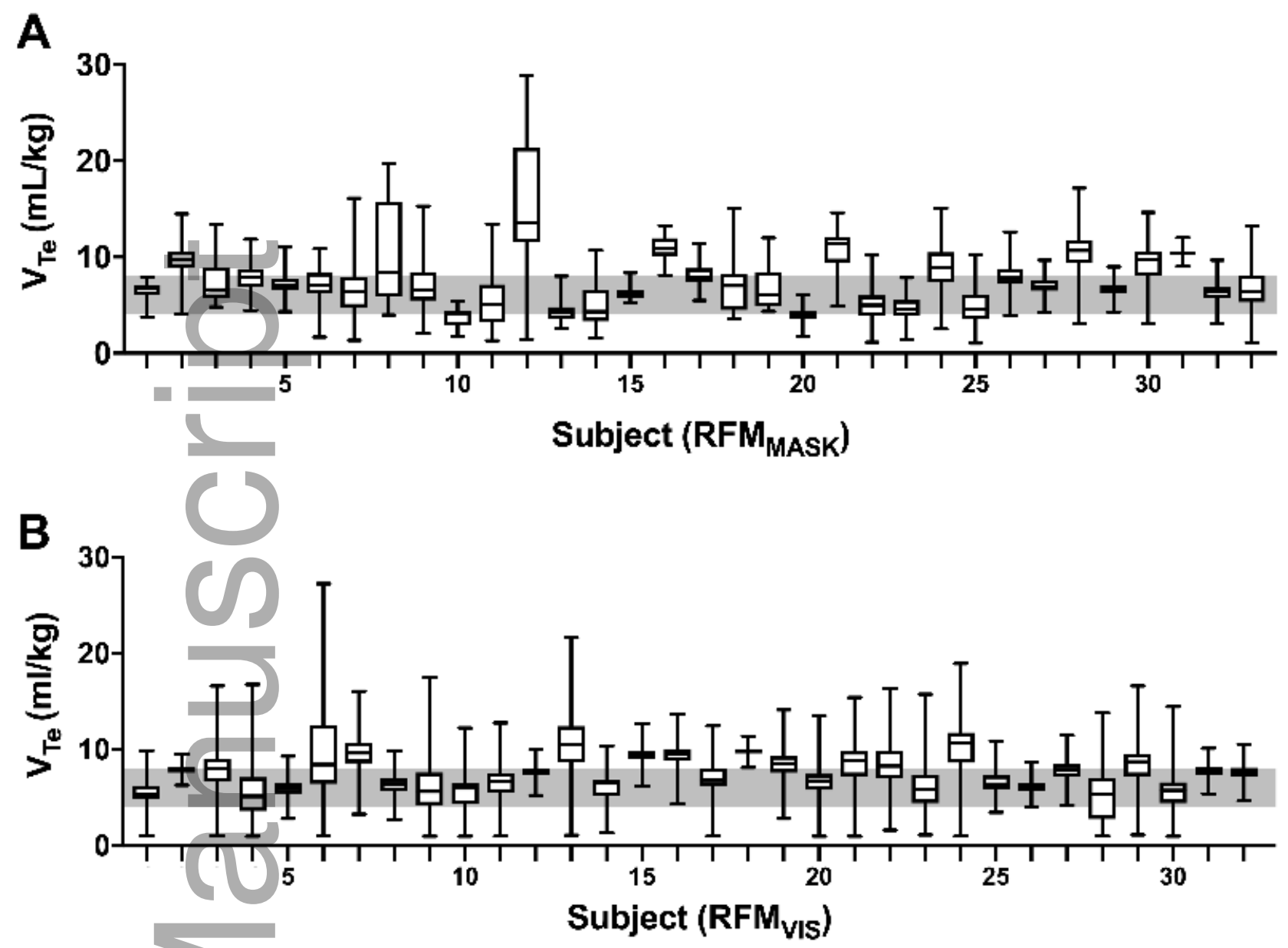

pan_13707_f1.tiff 


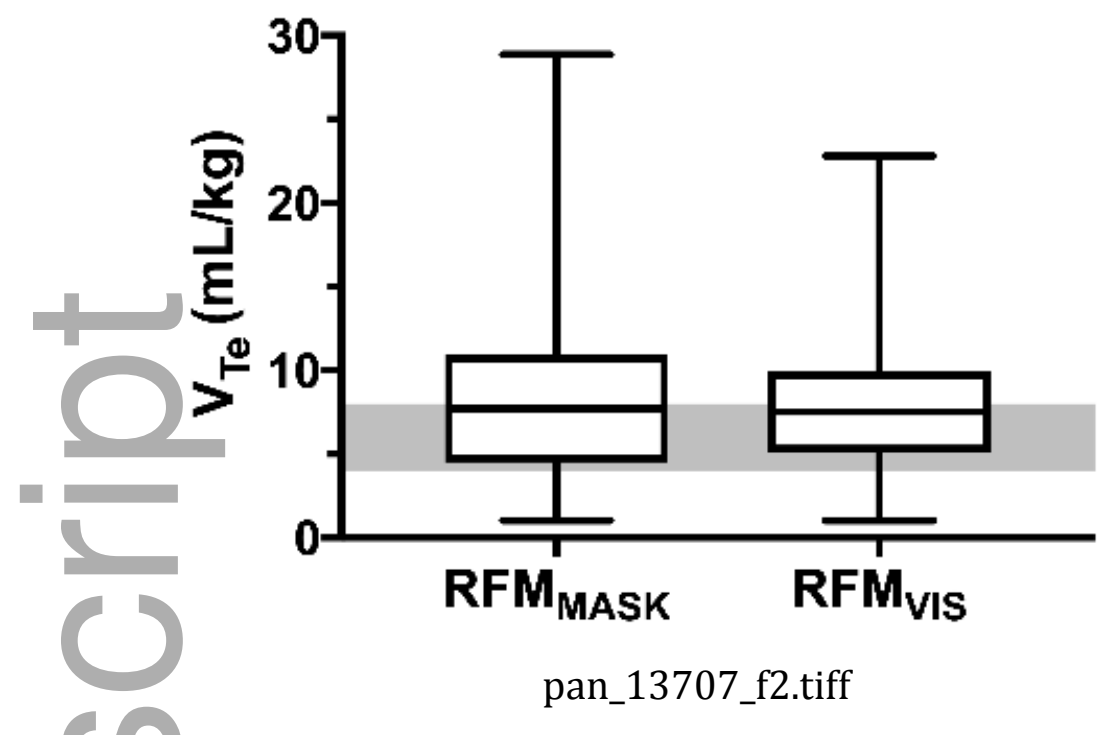

This article is protected by copyright. All rights reserved 


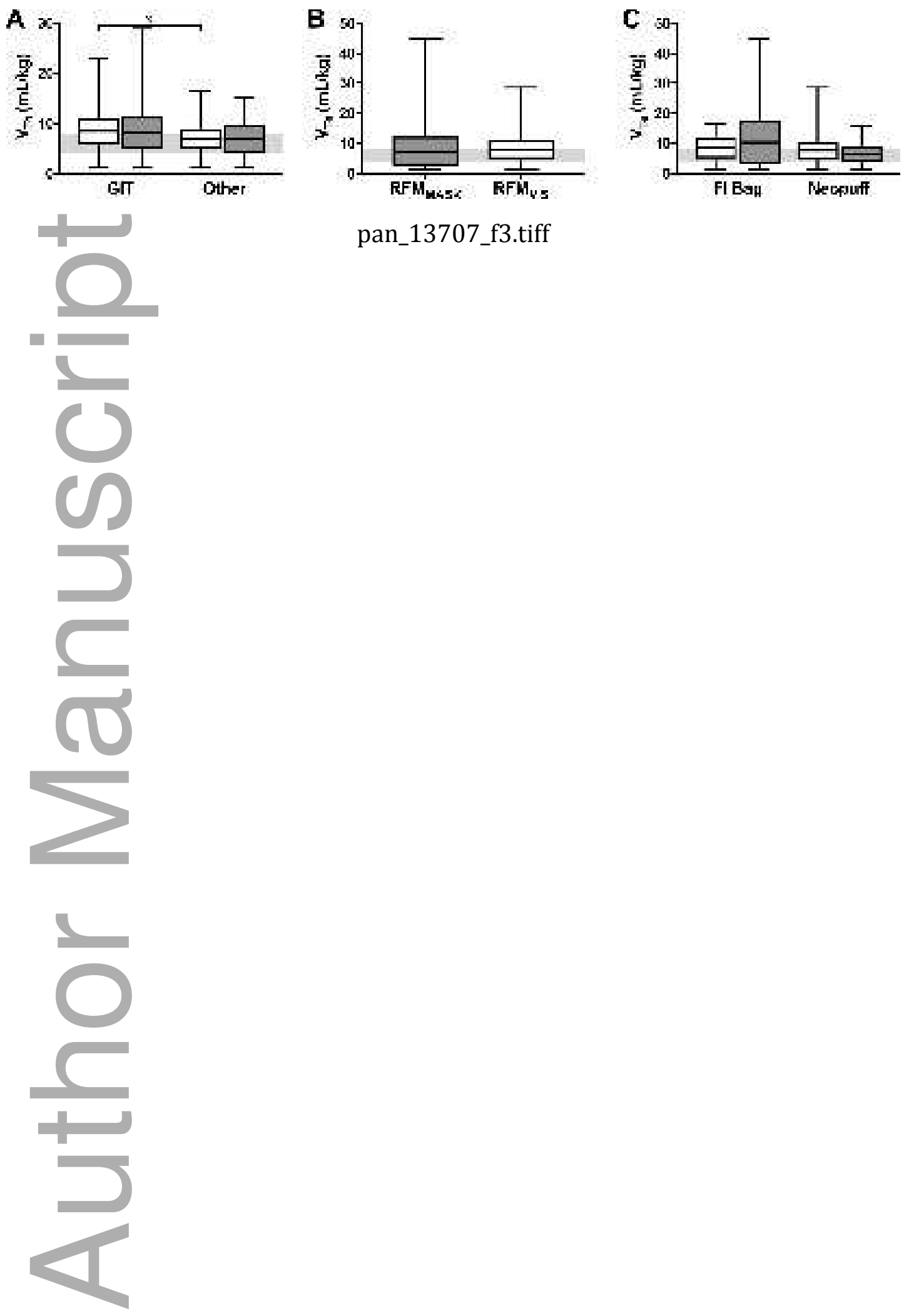

This article is protected by copyright. All rights reserved 


\section{University Library}

\section{- M M N E R VA A gateway to Melbourne's research publications}

Minerva Access is the Institutional Repository of The University of Melbourne

Author/s:

Atkins, WK;McDougall, R;Perkins, EJ;Pereira-Fantini, PM;Tingay, DG

Title:

A dedicated respiratory function monitor to improve tidal volume delivery during neonatal anesthesia

Date:

2019-08-12

Citation:

Atkins, W. K., McDougall, R., Perkins, E. J., Pereira-Fantini, P. M. \& Tingay, D. G. (2019). A dedicated respiratory function monitor to improve tidal volume delivery during neonatal anesthesia. PEDIATRIC ANESTHESIA, 29 (9), pp.920-926. https://doi.org/10.1111/ pan.13707.

Persistent Link:

http://hdl.handle.net/11343/286293 